\title{
ESTUDO SOBRE A VISÃO NO ESPORTE: O CASO DO FUTEBOL E DO FUTSAL
}

\section{A study about vision in sports like soccer and futsal}

\author{
Nelson Kautzner Marques Junior ${ }^{1}$ \\ ${ }^{1}$ Universidade Castelo Branco - Laboratório de Neuromotricidade Humana - RJ - Brasil
}

\begin{abstract}
Resumo: O funcionamento da visão é complexo, mas vários cientistas do esporte investigam sobre esse tema porque diversas tarefas das modalidades dependem da visão para uma boa execução. A maioria dos estudos sobre a visão no esporte acontecem no futebol. Talvez isso ocorra porque a literatura do futebol e dos seus derivados recomendam na partida ênfase na visão periférica. O objetivo da revisão foi de apresentar os estudos sobre a visão no futebol e no futsal. Foram selecionados cinco estudos, quatro sobre o futebol e um sobre o futsal. A primeira investigação mostrou como a visão atua numa tarefa defensiva, o segundo estudo evidenciou a percepção visual, na terceira pesquisa foi estudado o pênalti e no quarto estudo sobre o futebol foi abordado o conhecimento do resultado e a visão. A única investigação sobre o futsal foi sobre o aprendizado neuromotor, os atletas tiveram aquisição do treino da visão periférica. Em conclusão, pesquisar a visão no futebol e no futsal é importante porque o atleta desse esporte precisa jogar de cabeça erguida.

Palavras-chave: Visão, Esporte, Treino, Futebol, Futsal.
\end{abstract}

\begin{abstract}
The visual system is complex, but a lot of scientists have been studying about vision in sports due to its importance to take actions. Most studies about vision in sports take soccer into account. This is more likely to happen because literature shows playing soccer with emphasis on peripheral vision. The objective of the study was to show previous studies about vision in soccer and futsal. Four studies about vision in soccer were selected. The first study was about vision of the full-back, the second one was about visual perception, the third was about penalty and the last one was about knowledge of results. The only study about futsal was on neuromotor learning because indoor soccer players had peripheral vision training. In conclusion, researches about vision in soccer and futsal are important because soccer players and the indoor soccer players need emphasis on peripheral vision.
\end{abstract}

Key words: Vision, Sport, Training, Soccer, Indoor Soccer.

\section{INTRODUÇÃO}

O olho atua como uma câmera focalizando a imagem, a córnea faz refração para compactar o raio luminoso e a retina melhora a imagem. Em seguida, o raio luminoso que passa pela retina é convertido em impulso nervoso, chegando ao nervo óptico e caminhando para o quiasma óptico e depois para tracto óptico, onde esse impulso nervoso passa pelo núcleo geniculado lateral e proporciona a visão consciente ao atingir o córtex visual primário ou V1. Quando o impulso nervoso atinge o V1 ele vai para cada área específica do encéfalo responsável por um tipo de tarefa (cor, profundidade e outros)
(1). O funcionamento da visão é complexo (ver a obra de Bear, Connors e Paradiso ${ }^{(56)}$ para melhor compreensão), mas vários cientistas do esporte investigam sobre esse tema ${ }^{(2,3,4,5,6)}$ porque diversas tarefas das modalidades dependem da visão para sua boa execução. Os estudos da visão no esporte começaram através dos oftamologistas ${ }^{(7)}$, passando a ser praticado na Educação Física ${ }^{(8)}$. Entretanto, investigar como a visão atua num determinado esporte exige tecnologia muito sofisticada (uso de mini câmera próxima dos olhos) para identificar para onde o atleta está olhando durante a jogada $(9,10)$. Oudejans e Coolen ${ }^{(11)}$ evidenciaram que fazer o lance livre do basquetebol com os olhos vendados e com a 
visão difere na biomecânica do atleta. Harle e Vickers (12) identificaram que o lance livre do basquetebol é mais preciso se o atleta ficar olhando fixo para a cesta. No voleibol também foram conduzidas investigações sobre a visão ${ }^{(13,14)}$, o estudo mais interessante mostrou que para o atleta fazer a recepção do saque necessita olhar a bola e precisa se antecipar ao local onde o saque foi efetuado para realizar o passe ${ }^{(15)}$. Esta antecipação é necessária porque a alta velocidade que a bola vem em direção a quadra é o único meio de praticar a recepção. Mas para a antecipação ser eficaz depende de uma adequada informação visual. A informação visual referente a prática do árbitro ou do "bandeirinha" durante o acerto das regras já foi explicada pelos artigos de visão no esporte. Uma jogada do futebol possui velocidade superior ao da latência visual (cerca de 200 milésimos de segundo), não podendo o profissional da arbitragem (juiz ou auxiliar) captar o lance pelos olhos, tendo alta chance de erro ${ }^{(16)}$. Outro problema do profissional da arbitragem é o ângulo visual que ele se encontra durante a jogada (pode ser boa ou ruim) e a distância dessa autoridade em relação ao lance da partida, esses quesitos podem interferir na execução da regra (17). Somado a esses fatores que podem comprometer a visão do juiz ou do "bandeirinha", Nevill, Balmer e Williams ${ }^{(18)}$ observaram em sua pesquisa que o barulho durante a partida de futebol compromete a qualidade da arbitragem. Quanto menos barulho no jogo, melhor é a atuação do profissional da arbitragem. Então, torna-se urgente o uso do telão para ajudar o trabalho dos juízes.

Estudos sobre a visão no esporte já foram conduzidos em diversas modalidades (19,20,21,22), mas o esporte onde está concentrado a maioria das investigações é no futebol ${ }^{(23,24,25,26)}$. Talvez isso ocorra porque vários renomados autores afirmaram que jogar futebol de cabeça erguida com ênfase na visão periférica permite vantagem na prática dessa modalidade ${ }^{(27,28)}$. As mesmas afirmações são feitas para o futsal ${ }^{(29)}$. Para o atleta atuar na partida de cabeça erguida precisa realizar o treino da visão periférica ${ }^{(30)}$. Contudo, Lee, Legge e Ortiz ${ }^{(31)}$ alertaram que a visão central permite mais nitidez e a visão periférica é própria para tarefas que exigem noção espacial. Portanto, o atleta de futebol e dos seus derivados merece ser orientado como utilizar um tipo de visão para certo momento do jogo. Porém, como estudos sobre a visão no futebol e no futsal são pouco abordados na literatura nacional ${ }^{(32,33,34)}$, o intuito dessa revisão é apresentar as evidências científicas sobre a visão nessa modalidade. O objetivo da revisão foi de apresentar os estudos sobre a visão no futebol e no futsal.

\section{ESTUDO DA VISÃO NO FUTEBOL E NO FUTSAL}

No estudo de Williams e Davids (25) foram selecionados 12 experientes jogadores de futebol com 13,4 anos de treino e tendo $24 \pm 4,1$ anos. $O$ grupo de futebolistas iniciantes foi composto por 12 atletas com quatro anos de treino e tendo $23,3 \pm 4$ anos. Cada jogador de futebol do grupo experiente e do grupo iniciante fez uma vez de cada vez a tarefa da pesquisa, ficando numa distância de cinco metros de um telão que teve a imagem projetada pelo data show GEC LCD 15E de 20 seqüências ofensivas de três atacantes contra três defensores, o terceiro zagueiro era o atleta do estudo. Durante cada ataque, o sujeito da pesquisa deveria se antecipar a ação do armador do telão, realizando com os pés um toque no sensor que se encontrava no solo para estabelecer a escolha da sua antecipação nesta jogada. O sensor determinou o tempo de reação do sujeito em milésimos de segundo (ms), sendo modificado de Yarbus ${ }^{(35)}$ para o experimento. Através do sensor foi estabelecido o número de acertos durante a antecipação da marcação. O equipamento 4000SU Eye Movement Registration coletou através do reflexo da córnea com uma mini câmera presa no capacete a imagem ocular do jogador durante a antecipação da marcação. As imagens oculares foram encaminhadas para um computador, onde foi identificado para onde cada atleta do futebol olhou. A 
pesquisa foi conduzida num primeiro momento com a visão total e depois com a visão parcial, em cada tipo de visão aconteceram as 20 seqüências ofensivas. No $10^{\circ}$ Congresso Mundial de Psicologia do Esporte, Williams ${ }^{\left({ }^{36)}\right.}$ apresentou o equipamento desse estudo, sendo exposto na FIGURA 1:

\section{FIGURA 1}

EQUIPAMENTO DO ESTUDO DE WILLIAMS E DAVIDS (25).

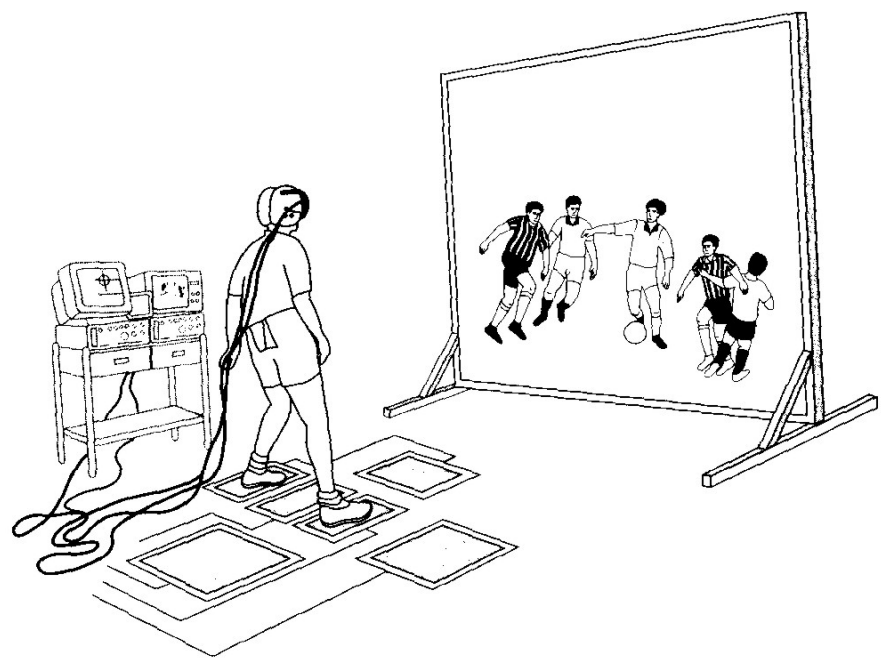

Os resultados do estudo de Williams e Davids (25) com a visão total mostraram através de Mancova diferença significativa (Wilks $=0,44, F(4,18)$ $=5,54, p=0,01)$ do tempo de reação entre os jogadores profissionais $(715 \pm 61,7 \mathrm{~ms})$ e iniciantes $(638,3 \pm 56,1 \mathrm{~ms})$. Os atletas profissionais tiveram o tempo de reação mais breve, sendo melhores do que os iniciantes. O número de acertos durante a antecipação da marcação não foi significativa $(p>0,05)$ entre profissionais e iniciantes. Porém, os jogadores profissionais tiveram mais acertos na antecipação da marcação $(81,3 \pm 10,9 \%)$ do que os iniciantes $(78,5 \pm 20,8 \%)$. A ordem da fixação visual a Anova one way $(F(1,22)=0,01)$ não detectou diferença significativa $(p>0,05)$ entre profissionais $(1,03 \pm 0,39)$ e iniciantes $(1,04 \pm 0,20)$. Os atletas olharam mais para as pernas do atacante que estava com a posse da bola. Enquanto que o local da fixação visual a Anova two way (2 grupos $x 4$ tipos de fixação visual) identificou diferença significativa $(p \leq 0,05)$ para grupo, $F(1,22)=$
0,08 . O teste posterior de Scheffé analisou os locais de fixação visual, identificando diferença significativa $(p \leq 0,05)$ para as pernas do atacante que estava com a bola do que as demais regiões (braços do jogador com a bola, lado esquerdo do atleta e lado direito do oponente). Isto ocorreu com os profissionais e com os iniciantes. Os resultados do primeiro experimento mostraram que os jogadores profissionais de futebol são mais rápidos na antecipação da marcação por causa de uma melhor habilidade visual que gera mais acertos durante essa tarefa. Enquanto que no segundo estudo de Williams e Davids ${ }^{(25)}$, ocorreu com oclusão visual, o mesmo material e método foi aplicado nos jogadores profissionais e iniciantes. Essa oclusão visual foi de dois tipos: no primeiro o atleta tinha um ângulo horizontal de $35^{\circ} \mathrm{e}$ um ângulo vertical de $30^{\circ}$ (denominada de oclusão parcial), o segundo o jogador tinha um ângulo horizontal de $6^{\circ} \mathrm{e}$ um ângulo vertical de $5^{\circ}$ (denominada de oclusão parcial). Neste segundo experimento o sensor no solo determinou o tempo da ação e o número de acertos da marcação durante o toque dos pés no sensor. Os resultados da pesquisa mostraram através de Mancova diferença significativa para grupo, (Wilks $=0,25, \mathrm{~F}(2,20)=4,17$, $p=0,05)$. O teste posterior de Scheffé identificou nos jogadores profissionais diferença significativa $(p \leq 0,05)$ no número de acertos da marcação com oclusão parcial $(80,8 \pm 13,1 \%)$ quando comparado com oclusão quase total $(62,5 \pm 15,4 \%)$. O tempo da ação Scheffé não mostrou diferença significativa $(p>0,05)$ entre a oclusão parcial $(4269,2 \pm 269,8 \mathrm{~ms})$ e a oclusão quase total $(4403 \pm 196,8 \mathrm{~ms})$ dos profissionais. Nos iniciantes do futebol não ocorreu diferença significativa $(p>0,05)$ no número de acertos com oclusão parcial $(77,5 \pm 12,2 \%)$ e com oclusão quase total $(70 \pm 15,9 \%)$. O mesmo aconteceu com os iniciantes no tempo da ação, foi insignificante $(p>0,05)$ com a oclusão parcial $(4563,9 \pm 276,1 \mathrm{~ms})$ e com a oclusão quase total $(4605,2 \pm 268,4)$. Contudo, o teste posterior de Scheffé mostrou que os jogadores de futebol profissional são mais rápidos significativamente $(p \leq 0,05)$ do que os iniciantes quando foi comparado 
o tempo da ação da oclusão parcial e da oclusão quase total. $O$ que chamou atenção nesse segundo estudo, que a oclusão quase total prejudicou em demasia o número de acertos da marcação dos profissionais, a causa para esses achados é que os jogadores profissionais utilizam muito a visão periférica. Já os futebolistas iniciantes, o tipo de oclusão não prejudicou nos acertos desses atletas porque a ênfase visual dessa amostra é pela visão central (jogam prioritariamente de cabeça baixa). Um dos achados desse segundo estudo esteve de acordo com a literatura do futebol ${ }^{(37)}$, os profissionais tem um tempo da ação mais veloz do que os iniciantes porque a percepção visual proveniente do maior uso da visão periférica acarreta este benefício.

A percepção visual de melhor qualidade gera uma antecipação mais veloz e com mais acertos na jogada do futebol ${ }^{(38)}$. Geralmente essa percepção visual é mais eficaz nos jogadores mais treinados. O movimento sacádico dos olhos (é o período de latência que leva o olhar de um ponto ao outro) tende ser mais breve em atletas treinados do que em iniciantes ${ }^{(39)}$, cerca 200 ms para o olho se pôr em movimento em esportistas treinados ${ }^{(40)}$. Também, o tempo de reação visual é mais breve em pessoas mais jovens (20 a 30 anos) e melhor em futebolistas altamente treinados ${ }^{(27)}$. Todas essas ocorrências visuais podem ter acontecido no estudo apresentado anteriormente, Williams e Davids ${ }^{25)}$, mas não foi mensurado. Entretanto, a percepção visual foi evidenciada na pesquisa de Williams, Weigelt, Harris e Scott ${ }^{(41)}$. Foram selecionados 54 jogadores do futebol escolar de diferentes idades. A amostra foi dividida em três grupos: tendo 15 futebolistas com $8,44 \pm 0,22$ anos, 18 atletas com 10,43 $\pm 0,3$ anos e 21 jogadores com $12,35 \pm 0,20$ anos. Nessa pesquisa 23 jogadores tinham a perna direita dominante e 11 o membro inferior esquerdo como o preferencial. Os jogadores foram classificados como habilidosos (oito anos com sete jogadores, 10 anos com nove futebolistas e 12 anos com 11 atletas) e iniciantes (oito anos com oito jogadores, 10 anos com nove futebolistas e 12 anos com 10 atletas) baseado na experiência esportiva e num pré-teste com cinco tentativas onde os jogadores tiveram uma pontuação (a mesma atividade da pesquisa). O Jugs (Tualatin) foi colocado numa distância de nove metros dos jogadores e lançou uma bola numa velocidade de 7,5 metros por segundo, onde o atleta tinha que dominar a bola de futebol numa região de 2,1×2,1 metros $(\mathrm{m})$. Essa tarefa foi realizada por 10 tentativas, pontuando quando o domínio era efetuado com os pés dentro da área de 2,1×2,1 m. Essas 10 tentativas foram feitas com a visão total e com a visão ocluída. Quando o futebolista fez a tarefa com a visão ocluída foi utilizado um óculos para propiciar essa condição visual. Os resultados do estudo evidenciaram através de Anova three way ( 2 grupos $\times 3$ idades $\times 2$ visões) diferença significativa para grupo, $F(1,40)=34,51, p=0,01$. Os atletas habilidosos (média $(M)=2,11$ ) foram melhores do que os iniciantes $(M=1,44)$. A pontuação da idade de 10 anos $(M=2,08)$ e de 12 anos $(2,21)$ foi significativamente maior do que a idade de oito anos $(M=1,03), F(2,40)=40,72, p=0,01$. A visão total $(M=2,02)$ teve uma pontuação superior do que a visão ocluída $(M=1,54)$ durante o domínio da bola, $F(1,46)=52,18, p=0,01$. As conclusões do estudo determinaram que o melhor desempenho dos habilidosos foi por causa da percepção visual mais desenvolvida e uso mais eficaz da visão periférica que acarreta mais acertos no domínio com os pés.

A performance visual influência na qualidade da tarefa ${ }^{(42)}$. O quiet eye (olho imóvel) consiste do atleta fixar o olho num alvo e praticar o fundamento da modalidade com precisão para o local desejado (15). Conforme a dificuldade da tarefa a duração do quiet eye pode ser curta ou longa ${ }^{(43)}$, geralmente atletas experientes possuem um quiet eye mais breve e conseguem mais sucesso na técnica esportiva ${ }^{(44)}$. O quiet eye talvez pode influenciar na precisão do chute para a meta, até a data presente não foi pesquisado no chute do futebol ${ }^{(45)}$, mas para o quiet eye funcionar precisa estar somado a uma boa inteligência de jogo ${ }^{(46)}$. Na investigação de Van 
Der Kamp ${ }^{(47)}$ participaram 10 jogadores de futebol com 22,8 $\pm 2,7$ anos que foram atletas amadores da Associação da Holanda de Futebol, sendo considerados esportistas medianos de futebol, mas esses futebolistas regularmente cobravam pênalti na competição com a perna direita. Esses esportistas eram estudantes de Educação Física da Universidade de Amsterdam. Os equipamentos utilizados nessa pesquisa quase-experimental foram uma grama sintética, um gol oficial (7,32 de largura por 2,44 m de altura), a marca do pênalti na distância oficial (11 $\mathrm{m})$, um alvo quadrado de $60 \times 60 \mathrm{~cm}$ marcado com linha preta foi feito no lado esquerdo e no direito do gol que se localizou $120 \mathrm{~cm}$ acima do solo, $120 \mathrm{~cm}$ de distância do travessão, $135 \mathrm{~cm}$ de distância do poste lateral do gol e $230 \mathrm{~cm}$ de distância do meio do gol. Esse alvo foi posto nesta região do gol porque é um local difícil para o goleiro defender, mas sendo comum a cobrança dos bons batedores de pênalti nesta região. Para indicar qual alvo o jogador de futebol deveria mirar, foi colocado duas lâmpadas de 100 watts para determinar o alvo (esquerda ou direita) que o jogador deveria acertar a bola, ou seja, numa distância de $2 \mathrm{~m}$ da marca do pênalti o pesquisador apertou um dos botões para ligar a lâmpada esquerda ou direita a fim de estabelecer o alvo para o jogador direcionar a cobrança do pênalti. Cada lâmpada de aviso do local do pênalti ficou $20 \mathrm{~cm}$ acima do solo e no meio do gol, sendo protegida por uma armação de ferro que ficou em volta da lâmpada. A FIGURA 2 expõe o gol com o alvo e as duas lâmpadas no centro do gol.

\section{FIGURA 2}

GOL DA PESQUISA DE VAN DER KAMP (47).

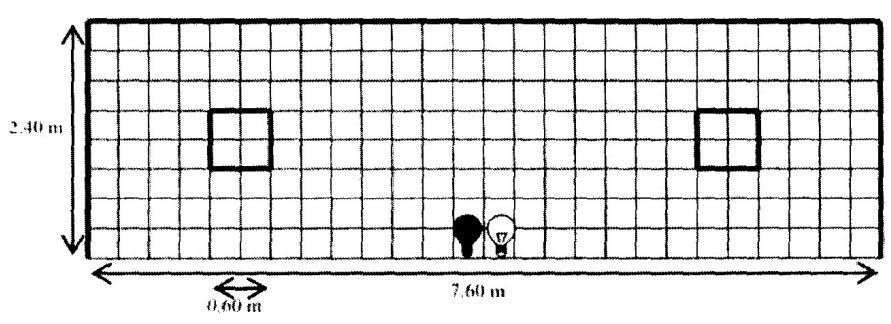

Os futebolistas para se acostumarem com o experimento fizeram por cinco a dez minutos diversas cobranças de pênalti. Depois foram realizados três blocos de pênalti para cada tipo de tarefa. O mesmo número de pênaltis foi realizado para o alvo da esquerda e para o alvo da direita em cada tarefa. $\mathrm{Na}$ tarefa $\mathrm{A}$ a luz que indica em qual alvo deve ser efetuado o pênalti era acessa antes da corrida de aproximação que antecede o chute do pênalti. A tarefa $B$ a luz que informava para onde deveria ser pênalti era acessa durante a corrida de aproximação. E na tarefa C, a luz era acessa no início da corrida de aproximação e podendo ser ligada novamente ou não durante o deslocamento em direção a bola. Durante a tarefa $\mathrm{C}$ o jogador partiu em direção a bola através de três tipos de distâncias $(2,4$ m, 1,6 m e $80 \mathrm{~cm})$, sendo avisado antes de realizar a corrida de aproximação através de uma bandeira que era exposta. A ordem da distância de partida da tarefa $\mathrm{C}$ não tinha uma ordem definida, sendo aleatória. Os resultados do estudo através de Anova three way para dados repetidos não foram significativos para os chutes sem gol $(F(2,18)=$ $0,58, p>0,05$ ) nas três tarefas (tarefa $A=9,3 \%$, tarefa $B=7,2 \%$ e tarefa $C=10,6 \%$ ). Mas no gol com erro da estratégia de acertar no alvo indicado pela luz foi significativo em Anova three way para dados repetidos $(F(2,18)=161, p \leq 0,0001)$. O teste posterior pairwise conduzido por Bonferroni foi significativo ( $p \leq 0,0001)$ entre a tarefa $C(25,4 \%)$ quando comparado com a tarefa $\mathrm{A}(0 \%)$ e com a tarefa $\mathrm{B}(1,5 \%)$. A tarefa $C$ foi pior do que as demais tarefas ( $A$ e $B$ ). Enquanto que a comparação entre a tarefa $A(0 \%)$ e $B(1,5 \%)$ foi significativa $(p \leq 0,04)$, sendo melhor o desempenho na tarefa $A$. Esses resultados mostraram que não se deve alterar a estratégia para efetuar o pênalti, por esse motivo a tarefa $A$ foi superior do que as demais. A Anova three way para dados repetidos foi significativa para os gols no alvo $(F(2,18)=6,13, p \leq 0,01)$. O teste posterior pairwise conduzido Bonferroni identificou diferença significativa $(p \leq 0,01)$ nas tarefas, onde a tarefa B $(93 \pm 44)$ e a tarefa C $(98 \pm 44)$ foram melhores do que a tarefa $A(88 \pm 32)$. Uma das causas para o 
desempenho superior da tarefa $\mathrm{B}$ e $\mathrm{C}$ no número de gols foi a maior atenção que essas atividades exigem dos jogadores. Também essas tarefas obrigam aos futebolistas um maior uso da visão periférica, vantajoso para atividades espaciais. Outro fator que pode ter ocasionado mais acertos durante o pênalti na tarefa B e C, foi a qualidade do quiet eye, mas não foi mensurado nessa investigação.

O feedback acontece por via intrínseca, onde a própria pessoa detecta o erro na tarefa ou a causa do acerto tentando desempenhar na próxima execução uma ação corrigida ou melhor do que a anterior ${ }^{(48)}$. O feedback intrínseco acontece através da visão, audição, propriocepção e tato. O feedback aumentado ocorre pela fonte externa, sendo acrescido mais informação ao feedback intrínseco ${ }^{(49)}$. Uma das categoria do feedback aumentado é o conhecimento do resultado ( $\mathrm{CR}$ ), onde o técnico informa ao atleta sobre o desempenho de uma habilidade neuromotora (boa ou ruim) ${ }^{(50)}$. O CR permite ao aprendiz do futebol aquisição ou retenção de um fundamento dessa modalidade ${ }^{(51)}$. Na pesquisa de Horn, Williams, Scott e Hodges ${ }^{(52)}$ foram selecionadas 24 mulheres

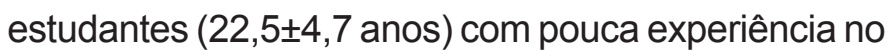
futebol. Todas as participantes fizeram um pré-teste que consistia de chutar uma bola de futebol por cinco tentativas numa distância de cinco metros por cima de uma barreira de $35 \mathrm{~cm}$ para acertar no meio do alvo de $64 \times 50 \mathrm{~cm}^{2}$. Após os resultados do pré-teste, as mulheres estudantes foram divididas em três grupos ( $n=8$ para cada grupo) que eram os seguintes: o grupo A teve o CR observando as imagens do acerto e do erro no alvo pelo vídeo cassete, o grupo $B$ teve o CR olhando a filmagem da biomecânica do chute referente o acerto e o erro do alvo pelo vídeo cassete e a terceira amostra foi o grupo controle, sem CR. O grupo A foi filmado pela câmera Panasonic M-40 (Tóquio, Japão) durante a execução dos chutes, essas imagens foram convertidas em VHS para essa amostra saber o CR sobre o acerto e erro no alvo. O grupo B foi filmado por quatro câmeras (Pro-Reflex, Qualisys, Gothenburg, Suécia) que registraram as ações do chute e de cada articulação desse fundamento que foram coletados por sensores (Q-Trac View Motion, Beta 2.54, Qualisys) fixados do ombro, quadril, joelho, tornozelo e no pé. Para o grupo B saber o CR sobre a biomecânica do chute que acertou e errou o alvo, as imagens foram convertidas em VHS para essa amostra ter acesso ao CR. Foram realizadas as mesmas tarefas do préteste (cinco chutes numa distância de cinco metros do alvo que deveria passar por cima de uma barreira de $35 \mathrm{~cm}$ ), a visão das participantes foi ocluída (pelo Plato S-2, Toronto, Canadá) quando a bola batia no alvo para não ocorrer o feedback intrínseco. Depois dos grupos se acostumarem com a visão ocluída quando a bola batia no alvo, foi feita uma tarefa de aquisição com 20 chutes para o alvo, o sujeito ficou cinco metros de distância do alvo e a bola tinha que passar por cima da barreira de $35 \mathrm{~cm}$. Terminada essa tarefa o grupo A e o grupo B tiveram acesso aos respectivos feedbacks extrínsecos através do CR. Continuando o experimento, foi feita pela segunda vez a familiarização com o equipamento da oclusão da visão quando a bola bate no alvo, essas mulheres estudantes fizeram cinco chutes na distância de cinco metros com a bola passando por cima da barreira de $35 \mathrm{~cm}$ e chegando no alvo. Em seguida, foi praticada outra tarefa de aquisição feita com 20 chutes para o alvo, o sujeito ficou cinco metros de distância do alvo e a bola tinha que passar por cima da barreira de $35 \mathrm{~cm}$. Terminada essa tarefa o grupo A e o grupo B tiveram acesso aos respectivos feedbacks extrínsecos através do CR. Para terminar as atividades do primeiro dia, foi praticado um pósteste com cinco chutes para o alvo e o grupo A e o grupo $B$ tiveram acesso ao $\mathrm{CR}$. No segundo e no terceiro dia, o grupo A, o grupo B e o grupo controle fizeram uma tarefa de retenção com cinco chutes para o alvo e tendo o equipamento de oclusão da visão. O grupo A e o B não tiveram acesso ao $C R$. Na segunda tarefa de retenção foi feita cinco chutes para o alvo e não foi usado o equipamento de oclusão da visão. O grupo A e o B tiveram acesso ao CR. Os 
resultados do estudo evidenciaram através de Anova two way para dados repetidos (3 grupos $\times 6$ testes) diferença significativa para teste, $F(2,64)=3,96$, $p=0,05$. O teste posterior de Tukey HSD detectou que os participantes exibiram significantemente $(p \leq 0,05)$ menos erro no pós-teste $(126,7 \pm 54,4 \mathrm{~cm})$ e na retenção com CR $(174,5 \pm 70,2 \mathrm{~cm})$. O grupo A, B e controle tiveram resultados parecidos no número de erros, a causa para esse ocorrido foi o não uso do feedback intrínseco da visão quando a bola batia no alvo. O GRÁFICO 1 expõe o erro em $\mathrm{cm}$ do alvo de cada amostra nos diversos momentos da pesquisa.

\section{GRÁFICO 1}

MÉDIA DE ERROS EM CENTÍMETROS CONFORME O PERÍODO DO ESTUDO

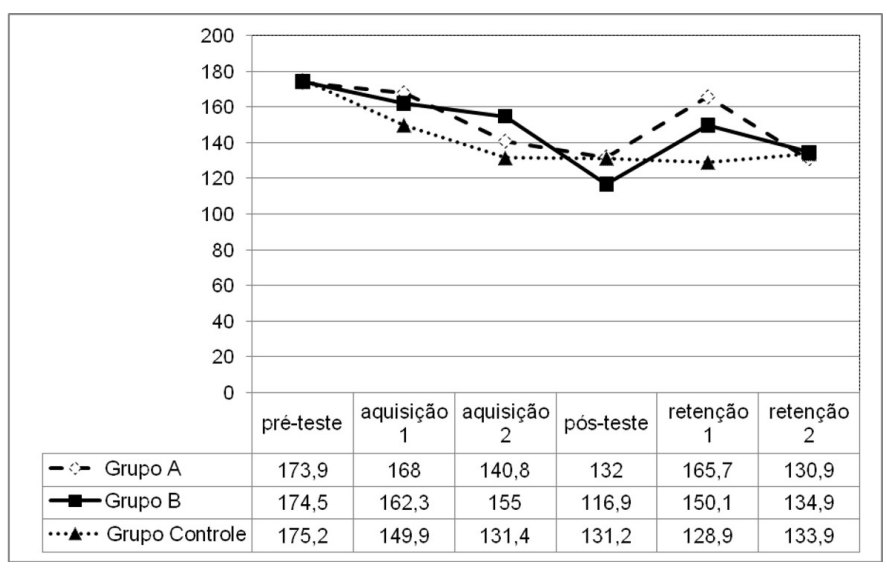

As práticas mais usadas no aprendizado neuromotor são constituídas pela prática em bloco e pela prática aleatória. Cada tipo de prática causa uma interferência contextual no praticante. Interferência contextual significa que a habilidade neuromotora efetuada por um tipo de prática do aprendizado neuromotor causa um tipo de interferência sobre o entendimento da tarefa exercitada ${ }^{(53)}$, ou seja, a memória pode ser mais ou menos exigida. A prática em bloco é indicada para ser prescrita para um sujeito quando uma habilidade neuromotora necessita de aquisição, ocorrendo baixa interferência contextual ${ }^{(54)}$. A prática em bloco ocorre uma seqüência pré-estabelecida de exercícios sempre na mesma ordem. Enquanto que a prática aleatória é eficaz quando uma amostra precisa de retenção de uma habilidade neuromora, acontecendo alta interferência contextual ${ }^{(55)}$. A prática aleatória ocorre numa seqüencia de exercícios não ordenada, ou seja, o foco do treino é exercitado e acontecem outros exercícios que prejudicam o objetivo da sessão causando constantemente reconstrução da memória sobre o foco da sessão. Na dissertação de mestrado de Marques Junior (56) foram selecionados 10 jogadores de futsal não federados da comunidade de Ititioca e Atalaia, Niterói, RJ, Brasil, participantes do projeto de esportes do Lar da Criança Padre Franz Neumair. O grupo experimental (GE) foi composto por cinco atletas com idade de 10 $\pm 2,82$ e o grupo controle (GC) por cinco jogadores com idade de 10,8 $\pm 1,92$ anos. A divisão da amostra foi intencional, sendo observada em duas sessões a qualidade técnica e tática do jogar futsal. O GE e o GC jogaram futsal com ênfase na visão central (de cabeça baixa) e durante as jogadas acontecia muita verbalização. O treinamento do GE e do GC foi o mesmo, a diferença que o GE praticou o treino da visão periférica que educa o atleta a jogar de cabeça erguida. Esses jovens treinaram duas vezes por semana ( $3^{a}$ e $5^{a}$ feira), de nove às dez horas da manhã, sendo a primeira vez que esses iniciantes tiveram um treinamento sistemático visando evoluir da recreação para a atividade esportiva. O modelo de periodização prescrito para os jogadores foi a periodização tática, em todas as sessões deve estar presente a bola. No macrociclo um foi realizado 30 minutos de treino técnico com variadas atividades (condução da bola, chute, drible e outros) e 30 minutos de jogo, sendo efetuada a prática em bloco em nove sessões. Após as nove sessões aconteceu o primeiro turno do campeonato em dupla de futsal que resultou nas seguintes colocações: campeão foi o GC A, vice-campeão foi o GE B, terceiro lugar foi o GE A e quarto lugar foi o GC B. No gol as posições foram: o goleiro do GE foi o primeiro e o GC ficou em segundo. No macrociclo dois foi realizado 30 minutos de treino situacional (dois contra dois na linha e tendo um goleiro) e 30 minutos de jogo, sendo efetuadas seis sessões (total de 15 sessões). Onde ocorreram duas práticas em bloco e quatro práticas aleatórias. 
Após as seis sessões aconteceu o segundo turno do campeonato em dupla de futsal que resultou nas seguintes colocações: campeão foi o GE B, vicecampeão foi o GE A, terceiro lugar foi o GC A e quarto lugar o GC B. No gol as posições foram: o goleiro do GE foi o primeiro e o GC ficou em segundo. Todos os jogos do campeonato em dupla o pesquisador se posicionou em cima de uma cadeira pouco afastada do campo e estando no meio da meia quadra. Para a filmagem do evento foram usadas a câmera Sony Handycam Vision CCD-TRV 12 e fita Sony Digital $8 \mathrm{~mm}$ com bateria Sony 360 minutos. Após a filmagem dos dois turnos, o autor iniciou-se a análise dos jogos por scout. O professor situou sua cadeira a $87 \mathrm{~cm}$ da televisão para identificar se o GE jogou de cabeça erguida. Para a marcação dos dados no scout usou prancheta, lapiseira e borracha, além de um pequeno banco que, próximo da cadeira pesquisador, foi usado para apoiar o controle remoto da filmadora e a própria prancheta quando necessário. A imagem da filmagem foi enviada diretamente da câmera para a televisão CCE 30 polegadas pelo fio ouro. Para cada tarefa de ataque (IO - início ofensivo, CDO - construção e desenvolvimento ofensivo e F - finalização) foi utilizado um scout, sendo riscado em que momento o atleta do GE ou do GC obteve um tipo de visão de 0 (visão central fraco) a 4 (visão periférica excelente). A estatística descritiva do grau da visão periférica no ataque é mostrada na TABELA 1.

A ANOVA two way (2 grupos $\times 2$ turnos) no início ofensivo determinou diferença significativa para o grupo $F(1,187)=64,88, p=0,001$, para o turno $F(1,187)=25,23, p=0,001$ e para a interação entre grupo e turno $F(1,187)=22,74$, $p$ $=0,001$. Essa interação foi investigada pelo teste " $\mathrm{t}$ " independente, as análises mostraram diferenças significativas em todos os cálculos sobre os graus da visão periférica no início ofensivo do GE em relação ao grupo controle GC. As comparações entre GC x GE foram as seguintes: $1^{\circ}$ turno do $\mathrm{GC} \times 1^{\circ}$ turno do GE (t $(92)=-7,85, \mathrm{p}=0,001$, tamanho do efeito $(\mathrm{d})=1,74$ (grande), $25 \%$ de sobreposição), $2^{\circ}$ turno do GC x $2^{\circ}$ turno do GE (t $(95)=-2,80, p=0,006, d=0,60$ (médio), 67\%), $1^{\circ}$ turno do GC x $2^{\circ}$ turno do GE (t $(94)=-8,43, p=$ $0,001, d=2,4$ (grande), $16 \%$ ) e $2^{\circ}$ turno do $G C x$ $1^{\circ}$ turno do GE (t (93) $=-2,40, p=0,018, d=0,50$ (médio), 67\%). Na construção e desenvolvimento ofensivo, a ANOVA two way (2 grupos x 2 turnos) detectou diferença significativa para o grupo $F$ $(1,218)=355,99, p=0,001$ e para o turno $F$ $(1,218)=7,82, p=0,001$, não foram encontradas diferenças para a interação entre grupo e turno na construção e desenvolvimento ofensivo $F(1,218)$ $=0,16, p=0,68$. Enquanto que na finalização, a ANOVA two way (2 grupos x 2 turnos) revelou diferença significativa para o grupo $F(1,167)=$ $241, p=0,001$, contudo, esse modelo estatístico na finalização não identificou diferença significativa para o turno $F(1,167)=0,31, p=0,64$ e para a

TABELA 1

GRAU DA VISÃO PERIFÉRICA (VP) NAS FASES DO ATAQUE

\begin{tabular}{ccccccc}
\hline Grupo & $\begin{array}{c}\text { VPIO } \\
\mathbf{1}^{\circ} \text { turno }\end{array}$ & $\begin{array}{c}\text { VPIO } \\
\mathbf{2}^{\circ} \text { turno }\end{array}$ & $\begin{array}{c}\text { VPCDO } \\
\mathbf{1}^{\circ} \text { turno }\end{array}$ & $\begin{array}{c}\text { VPCDO } \\
\mathbf{2}^{\circ} \text { turno }\end{array}$ & $\begin{array}{c}\text { VPF } \\
\mathbf{1}^{\circ} \text { turno }\end{array}$ & $\begin{array}{c}\text { VPF } \\
\mathbf{2}^{\circ} \text { turno }\end{array}$ \\
\hline Experimental & $\begin{array}{c}2,52 \pm 1,90 \\
\text { médio }\end{array}$ & $\begin{array}{c}0,72 \pm 1,37 \\
\text { muito fraco }\end{array}$ & $\begin{array}{c}3,31 \pm 1,38 \\
\text { Bom }\end{array}$ & $\begin{array}{c}2,82 \pm 1,65 \\
\text { médio }\end{array}$ & $\begin{array}{c}3 \pm 1,64 \\
\text { bom }\end{array}$ & $\begin{array}{c}2,83 \pm 1,70 \\
\text { médio }\end{array}$ \\
Controle & $\begin{array}{c}0,17 \pm 0,80 \\
\text { muito fraco }\end{array}$ & $\begin{array}{c}0,12 \pm 0,62 \\
\text { muito fraco }\end{array}$ & $\begin{array}{c}0,38 \pm 1,10 \\
\text { muito fraco }\end{array}$ & $\begin{array}{c}0,01 \pm 0,10 \\
\text { muito fraco }\end{array}$ & $\begin{array}{c}0,02 \pm 0,15 \\
\text { muito fraco }\end{array}$ & $\begin{array}{c}0,03 \pm 0,15 \\
\text { muito fraco }\end{array}$ \\
\hline
\end{tabular}


interação entre grupo e turno $F(1,167)=0,22, p$ $=0,63$. Em conclusão, parece que o GE obteve aquisição do treino da visão periférica porque as médias foram superiores as do GC, mas não melhorou seus resultados no segundo turno. Outra causa de parecer que o GE conseguiu aquisição do treino da visão periférica foi o fato da pesquisa não utilizar mini câmera para identificar para onde essa amostra estava olhando. Através dessa revisão o leitor teve acesso a alguns estudos sobre a visão no futebol e no futsal, podendo observar que esse tipo de pesquisa necessita de tecnologia de ponta para ser efetuado com qualidade.

\section{CONCLUSÃO}

Os estudos sobre a visão no futebol e no futsal são pouco praticados no Brasil, talvez a causa seja a onerosa instrumentação que esse tipo de investigação exige. Contudo, pesquisar a visão nessa modalidade é extremamente importante porque o atleta desse esporte necessita de jogar com ênfase na visão periférica.

\section{REFERÊNCIAS BIBLIOGRÁFICAS}

1. Shipp S. The importance of being agranular: a comparative account of visual and motor córtex. Phil Trans R Soc 2006;360:797-814.

2. Abernethy $B$, Neal RJ. Visual characteristics of clay target shooters. J Sci Med Sport 1999;2:1-19.

3. Abernethy B, Gill DP, Parks SL, Packer ST. Expertise and the perception of kinematics and situational probability information. Perception 2001;30:233-52.

4. Beckerman S, Hitzeman SA. Sport vision testing of selected athletic participants in the 1997 and 1998 AAU Junior Olympic Games. Optometry 2003;74:502-16.

5. Lemmink KAPM, Dijkstra B, Visscher C. Effects of limited peripheral vision on shuttle sprint performance of soccer players. Percept Mot Skills 2005;100:167-75.

6. Montés-Micó R, Bueno I, Candel J, Pons A. Eye-hand and eye-foot visual reaction times of young soccer players. Optometry 2000;71:775-80.
7. Stine CD, Arterburn MR, Stern NS. Vision and sports: a review of the literature. J Am Optom Assoc 1982;53:627-33.

8. Moreno FJ, Luis V, Salgado F, García JA, Reina R. Visual behavior and perception of trajectories of moving objects with visual occlusion. Percept Mot Skills 2005;101:13-20.

9. Panchuk D, Vickers JN. Gaze behaviors of goaltenders under spatial-temporal constraints. Hum Mov Sci 2006;25:733-52.

10. Reina R, Moreno FJ, Sanz D. Visual behavior and motor responses of novice and experienced wheelchair tennis player relative to the service return. Adapt Physic Activit Q 2007;24:254-71.

11. Oudejans RRD, Coolen B. Human kinematics and event control: on-line movement registration as a means for experimental manipulation. J Sports Sci 2003;21:567-76.

12. Harle SK, Vickers JN. Training quiet eye improves accuracy in the basketball free throw. Sport Psychol 2001;15:289-305.

13. Jafarzadehpur E, Aazami N, Bolouri B. Comparision of saccadic eye movements and facility of ocular accommodation in female volleyball players and nonplayers. Scand J Med Sci Sports 2007;17:186-90.

14. Lenoir M, Vansteenkiste J, Vermeulen J, Clercq DD. Effects of contrasting colour patterns of the ball in the volleyball reception. J Sports Sci 2005;23:871-9.

15. McPherson SL, Vickers JN. Cognitive control in motor expertise. Int J Sport Exerc Psychol 2004;2:274-300.

16. Maruenda FB. Can the human eye detect an offside position during a football match? Brit Med J 2004;329:1825.

17. Baldo MV, Ranvaud RD, Morya E. Flag errors in soccer games: the flash-lag effect brought to real life. Perception 2002;31:1205-10.

18. Nevill AM, Balmer NJ, Williams M. The influence of crowd noise and experience upon refereeing decision in football. Psychol Sport Exerc 2002;3:261-72.

19. Abernethy B, Wood JM. Do generalized visual training programmes for sport really work? An experimental investigation. J Sports Sci 2001;19:203-22.

20. Beckerman S, Fornes AM. Effects of changes in lighting level on performance with the AcuVision 1000. J Am Optom Assoc 1997;68:243-9. 
21. Bennett S, Button C, Kingsbury D, Davids K. Manipulating visual informational constraints during practice enhances the acquisition of catching skill in children. Res $Q$ Exerc Sport 1999;70:220-32.

22. Wood JM, Abernethy B. An assessment of the efficacy of sports vision training programs. Optom Vision Sci 1997;74:646-59.

23. Paillard T, Noé F. Effect of expertise and visual contribution on postural control in soccer. Scand J Med Sci Sports 2006;16:345-8.

24. Paillard T, Noé F, Rivière T, Marion V, Montoya R, Dupui P. Postural performance and strategy in the unipedal stance of soccer players at different levels of competition. J Athlet Train 2006;41:172-6.

25. Williams M, Davids K. Visual search strategy, selective attention, and expertise in soccer. Res $Q$ Exerc Sport 1998;69:111-28.

26. Williams M, Hodges NJ. Practice, instruction and skill acquisition in soccer: challenging tradition. J Sports Sci 2005;23:637-650.

27. Ando S, Kida N, Oda S. Central and peripheral visual reaction time of soccer players and nonathletes. Percept Mot Skills 2001;92:786-94.

28. Gréhaigne J-F, Godbout P, Bouthier D. The teaching and learning of decision making in team sports. Quest 2001;53:59-76.

29. Navarro AC, Almeida R. Futsal. São Paulo: Phorte, 2008.

30. Pinto JÁ, Araújo NI. Aimportância do treinamento da visão periférica no futebol. Rev Min Educ Fís 1999;7:81-93.

31. Lee H-W, Legge GE, Ortiz A. Is word recognition different in central and peripheral vision? Vision Res 2003;43:2837-46.

32. Cunha SA, Binotto MR, Barros, RML. Análise da variabilidade na medição de posicionamento tático no futebol. Rev Paul Educ Fís 2001;15:111-6.

33. Marques Junior NK. Solicitação metabólica no futebol profissional masculino e o treinamento cardiorrespiratório. Rev Corpoconsciência 2004;13:25-58.

34. Queiroga MR, Ferreira SA, Pereira G, Kokubun E. Somatotipo como indicador de desempenho em atletas de futsal feminino. Rev Bras Cineantropom Desempenho Hum 2008;10:56-61.
35. Yarbus, A. L. Eye movements and vision. New York: Plenum Press, 1967.

36. Williams M. Perceptual expertise in sport: some myths and realities. 10th World Congress of Sport Psychology; 2003 206-11;Skiathos, Greece.

37. Williams M. Perceptual and cognitive expertise in sport. Psychol 2002;15:416-7.

38. Ford P, Hodges NJ, Huys R, Williams M. The role of external action-effects in the execution of a soccer kick: a comparison across skill level. Mot Contr 2006;10:386404.

39. Robertson EM, Pascual-Leone A, Miall RC. Current concepts in procedural consolidation. Nature Rev 2004;5:1-7.

40. Rougier P, Garin M. Performing saccadic eye movements or blinking improves postural control. Mot Contr 2007;11:213-23.

41. Williams M, Weigelt C, Harris M, Scott MA. Age-related differences in vision and proprioception in a lower limb interceptive task: the effects of skill level and practice. Res Q Exerc Sport 2002;73:386-95.

42. Stoffregen TA, Bardy BG, Bonnet CT, Hove P, Oullier $O$. Postural sway and the frequency of horizontal eye movements. Mot Contr 2007;11:86-102.

43. Williams M, Singer RN, Frehlich SG. Quiet eye duration, expertise, and task complexity in near and far aiming tasks. J Mot Behav 2002;34:197-207.

44. Williams M, Janelle CM, Davids K. Constraints on the search for visual information in sport. Int J Sport Exerc Psychol 2004;2:301-18.

45. McGarry T, Franks IM. On winning the penalty shoot-out in soccer. J Sports Sci 2000;18:401-409.

46. Costa JC, Garganta J, Fonseca A, Botelho M. Inteligência e conhecimento específico em jovens futebolistas de diferentes níveis competitivos. Rev Port Ciên Desp 2002;2:7-20.

47. Van Der Kamp J. A field simulation study of the effectiveness of penalty kick strategies in soccer: late alterations of kick direction increase errors and reduce accuracy. J Sports Sci 2006;24:467-77.

48. Magill RA. Aprendizagem motora: conceitos e aplicações. $5^{\mathrm{a}}$ ed. São Paulo: Edgard Blücher, 2000. 
49. Chiviacowsky S, Wulf G. Self-controlled feedback is effective if it is based on the learner's performance. Res Q Exerc Sport 2005;76:42-8.

50. Guadagnoli MA, Lee TD. Challenge point: a framework for conceptualizing the effects of various practice conditions in motor learning. J Mot Behav 2004;212-24.

51. Ford $P$, Hodges NJ, Williams M. Examining action effects in the execution of a skilled soccer kick by using erroneous feedback. J Mot Behav 2007;39:481-90.

52. Horn RR, Williams M, Scott MA, Hodges NJ. Visual search and coordination changes in response to video and point-light demonstrations without KR. J Mot Behav 2005;37:265-74.

53. Wright DL, Magnuson CE, Black CB. Programming and reprogramming sequence timing following high and low contextual interference practice. Res Q Exerc Sport 2005;76:258-66.

54. Simon DA, Bjork RA. Models of performance in learning multisegment movement tasks: consequences for acquisition, retention, and judgments of learning. J Exper Psychol Appl 2002;8:222-32.

55. Perez CR, Meira Junior C, Tani G. Does the contextual interference effect last over extended transfer trials? Percept Mot Skills 2005;100:58-60.

56. Marques Junior NK. O efeito do treino da visão periférica no ataque de iniciados do futsal: um estudo na competição [dissertação]. Rio de Janeiro: UCB; 2008. 157 p.

57. Bear MF, Connors BW, Paradiso MA. Neurociências: desvendando o sistema nervoso. $2^{\mathrm{a}}$ ed. Porto Alegre: Artmed, 2002.

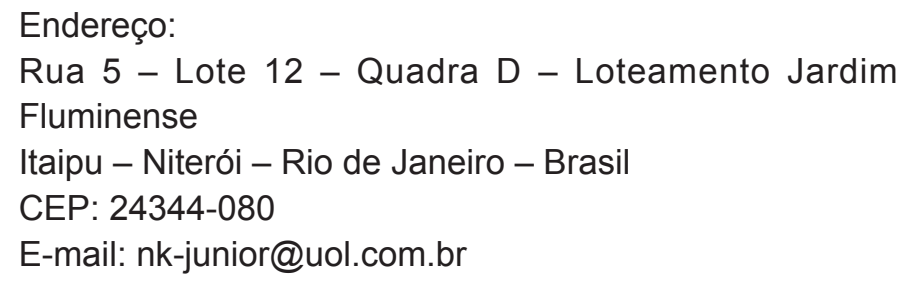

